Three kits are at present available, for single-beam and double-beam oscilloscopes and for a valve voltimeter.

Several counting and scaling units were shownone which provided some relatively light relief was arranged to measure one's reaction time. The victim was required to press a button when some miniature traffic lights turned red. The time taken in microseconds was duly counted and displayed; it was usually of the order of $2 \times 10^{5}$.

The research section showed a change from previous years in that there were no university exhibits, but three by national organizations: the Admiralty, Atomic Energy Research Establishment, Capenhurst, and the British Railways Research Department. The last-named was showing a train control system which automatically applies the brakes of a train passing a signal at danger. The Hall effect in an indium antimonide probe attached to the train is used for detecting the energization of an electromagnet between the tracks. This equipment, which is still in the experimental stage, is intended as an allelectronic successor to the electro-mechanical system now going into service.

J. E. GEAKE

\section{ENGINEERING TRAINING IN THE BRITISH BROADCASTING CORPORATION}

$\mathrm{T}$ HE series of B.B.C. Engineering Monographs, to which reference has already been made in Nature $(177,519 ; 1956)$, provide a continuous description of the technical equipment and operation of the Corporation, developed and applied to the conduct of its duties as a public broadcasting authority. Among these duties is that of recruiting and training the large numbers of engineers and technical personnel required by the organization.

B.B.C. Engineering Monograph No. $11^{*}$ is entitled "Engineering Training in the B.B.C.", by Dr. K. R. Sturley, and this describes the work of the training department which came into existence about eleven years ago, and is established at Wood Norton Hall, Evesham. Here there is accommodation for up to two hundred residential students, and full teaching facilities during various courses of instruction, which vary in length from one or two up to twelve weeks. The aims of the training department are to develop the skill and capabilities of staff, to encourage them to adopt a constructive attitude to new ideas and to increase the efficiency of the individual to the mutual benefit of himself and of the organization to which he belongs. Every attempt is made to avoid duplicating the basic training in electrical engineering which is provided by universities and technical colleges; the department concentrates on the application of basic principles to the equipment and methods used in broadcasting.

Some of the courses provide training for newly recruited entrants to the operating and technical assistant staffs, where the instruction varies from the arrangement of studio lighting to the maintenance of high-power transmitters. More advanced courses are intended to provide junior staff with opportunities for promotion in the operations or maintenance

* B.B.C. Engineering Monograph No. 11 : Engineering Training in the B.B.C. By Dr. K. R. Sturley. Pp. 24. (London: British Broadcasting Corporation, 1957.) $5 s$. fields. Students with the appropriate national technical qualification may be exempt from the first part of this course; they are then required to take the second part, dealing with broadcasting equipment and technique which cannot be a part of the syllabus leading to an academic award. At a more advanced level there is a graduate apprentice course of two years duration, involving attachment to other departments of the B.B.C. as well as the training department. Its purpose is to produce a wellbalanced man of wide experience, who will eventually qualify for corporate membership of his appropriate professional institution. Two types of graduates are sought here : one intended for specialist departments such as those conducting research or design and development; the other is intended to fill a senior position in the operation and maintenance branch, where the ability to supervize staff and to deal coolly and efficiently with an emergency are essential qualities.

Under Dr. Sturley as head of the Training Department, the instruction is organized in four sections dealing with fundamentals, radio-frequency transmission, studio and recording techniques, and operations; a fully qualified staff of lecturers, demonstrators and laboratory assistants is provided. A separate section of staff is responsible for the production of training manuals, and also of booklets on such subjects as television lighting, frequency modulation and slot aerials, which are of great value to the technical staff of the Corporation.

During July 22-26 last, a summer school was held at Wood Norton and was attended by some thirty members of the staffs from the engineering and physics departments of universities and technical colleges in the United Kingdom. In addition to inspecting the Training Department and witnessing demonstrations in the laboratories, a series of lectures was given by members of various departments of the B.B.C., the subjects ranging from training, research and operation to the presentation of science in sound and television broadcasting. The programme naturally included talks on the engineering and technical requirements of the B.B.C. staffs, and there was ample opportunity for both formal and informal discussion between the visitors and the resident staff. This short and very successful summer school, which was a repetition on an expanded scale of one held in 1952, should do much to strengthen the ties between the Corporation and the colleges on which it must rely for its recruits.

\section{TRAINING OF FACTORY WORKERS}

$T$ HE effectiveness of the training of factory workers has an important bearing on industrial productivity. Developments of production methods in this century, particularly in some of the newer industries, have made it possible to employ large proportions of semi-skilled and unskilled workers in the factories; the training of this kind of operative has been relatively neglected until recent years, presumably on the assumption that, because his work was simple in comparison with that of the craftsman, he would be able to learn it with a minimum of assistance. 